Research Article

Open Access

\title{
Effect of Smoking on Ocular Surface and Tear Film: A Clinico Pathological Study
}

\author{
Nikhil Agrawal ${ }^{1 \star}$, MK Jharawal $^{1}$, Nidhi Paharia ${ }^{2}$ and Kavita Bansal ${ }^{2}$ \\ ${ }^{\prime}$ Upgraded Department of Ophthalmology, SMS Medical College, Jaipur, India \\ ${ }_{2}^{2}$ Mahatama Gandhi Medical College, Jaipur, India
}

\section{Article Info}

\author{
*Corresponding author: \\ Nikhil Agrawa \\ Department of Ophthalmology \\ Upgraded department of Ophthalmology \\ SMS Medical College \\ Jaipur \\ India \\ Tel: 7357116809 \\ E-mail: nikhil.aiims87@gmail.com
}

Received: September 24, 2018

Accepted: October 9, 2018

Published: October 15, 2018

Citation: Agrawal N, Jharawal MK, Paharia N, Bansal K. Effect of Smoking on Ocular Surface and Tear Film: A Clinico Pathological Study. Madridge J Ophthalmol. 2018; 3(1): 39-42. doi: 10.18689/mjop-1000112

Copyright: (c) 2018 The Author(s). This work is licensed under a Creative Commons Attribution 4.0 International License, which permits unrestricted use, distribution, and reproduction in any medium, provided the original work is properly cited.

Published by Madridge Publishers

\begin{abstract}
Aim: Smoking is an important risk factor for many chronic diseases, however its association with dry eyes is still unclear. The study was undertaken to evaluate the effect of smoking on ocular surface clinically and its correlation pathologically with the help of impression cytology.

Methods: The study was conducted on 100 patients aged 18 to 50 years. The study group on the basis of number of cigarettes consumed, was further subdivided in mild ( $<10$ cigarettes per day) moderate (10-20 cigarettes per day) and heavy smokers ( $>20$ cigarettes per day). OSDI score, TBUT (tear film break up time), Basal tear secretion (Schirmer test 2), and conjunctival impression cytology were were performed.
\end{abstract}

Results: The study comprises 100 patients, 50 smokers and 50 age matched non smokers. The mean age of the smoker 35.5 years \pm 7.64 years and the mean age of non smokers in control group was $33.60 \pm 5.54$ years Mean tear film break up time in non smoker was $14.71 \pm 4.34 \mathrm{sec}$ as compared to $11.25 \pm 2.29$ seconds in smokers $(p=0.0001)$. Mean score of Schirmer's test was $12.58 \pm 2.79$ seconds in non smokers as compared to $10.40 \pm 2.64$ seconds in smokers with significant statistical difference $(p=0.001)$. On impression cytology, $20 \%$ of the subjects in smoker group shows grade 2 metaplasia and $8 \%$ showed grade 3 metaplasia in comparison to $2 \%$ and $0 \%$ in non smoker group respectively $(p=0.0001)$.

Conclusion: Smoking is a significant risk factor in the development of dry eyes and ocular surface disorder characterised by squamous metaplasia and loss of goblet cells. Furthermore the severity of dry eyes has positive correlation with amount of smoking.

Keywords: Ocular surface disorder, Dry eyes, Impression cytology.

\section{Introduction}

Tobacco smoking is a serious public health problem which contains various heavy metals and toxic mineral elements that has been associated with cardiovascular and respiratory disorders. Tobacco smoke contain more than 4000 compounds and a puff of smoke contain 300 million to 3.5 billion particles existing either in gas or particulate form which on exposure are eventually toxic to ocular tissue and affect eye through ischemic and oxidative mechanism [1].

Tobacco smoking is not only associated with cataract [2], ARMD [3], AION and toxic optic neuropathy but also with dry eye syndrome. Ocular surface is highly sensitive to air borne chemical fumes and irritative gas and its persistent exposure may lead to ocular surface damage and dry eye syndrome. Environment, lifestyle, age, sex, drug history, and systemic diseases are the major risk factor associated with dry eyes, among which the lifestyle factors may play an important role [4]. 
Smoking is already known as an important risk factor for many chronic diseases and however is still an unclear risk factor of dry eye. A number of studies [5] have evaluated the association between smoking and dry eye, however the results are disputed. The study was undertaken to evaluate the effect of smoking on ocular surface clinically and its correlation pathologically with the help of impression cytology.

\section{Subjects and Methods}

The study was conducted on 100 patients aged 18 to 50 years, in the upgraded departments of ophthalmology, SMS medical college, jaipur, India with the prior approval from Ethics committee of SMS Medical College. Informed consent was obtained from each subject, and the study was performed in accordance with the declaration of Helsinki. Subjects were divided in two groups, smokers (study group) and non smokers (control group). The study group on the basis of number of cigarettes consumed, was further subdivided in mild (<10 cigarettes per day) moderate (10-20 cigarettes per day) and heavy smokers ( $>20$ cigarettes per day). Patients with history of occupational exposure, contact lens use within 6 months of study, drug abuse, allergy, and systemic disease were excluded from the study.

Subjective and objective evaluation of patients was done for dry eyes which included OSDI score [6], TBUT (tear film break up time), Basal tear secretion (Schirmer's test 2), and conjunctival impression cytology. Patients were given questionnaire and symptom scoring was done according to OSDI score. Average score was calculated. Which ranges from 0 to 100 , with higher scores indicating more problems or symptoms.

Conjunctival impression cytology was performed in each eye of the patients and the control subjects. The samples were collected from the temporal interpalpebral bulbar conjunctiva. After instillation of a single drop of proparacaine $0.5 \%$, the cellulose acetate filter paper was applied over the temporal interpalpebral bulbar conjunctiva at distance of 3 $\mathrm{mm}$ from the limbus. Following $95 \%$ of alcohol fixation for at least $10 \mathrm{~min}$, the specimen was stained with periodic acidSchiff and hematoxylin, The cytologic changes are graded according to the Nelson's grading system.

Grade 0: Small and round epithelial cells with eosiniphilic staining cytoplasm. Nucleocytoplasmic ratio 1:2, abundant, plump, oval goblet cells with intensely PAS-positive cytoplasm.

Grade 1: Slightly larger and more polygonal epithelial cells with eosinophilic staining cytoplasm. Nucleo-cytoplasmic ratio 1 :3.There is decrease in goblet cell number.

Grade 2: Larger and polygonal, occasionally multinucleated epithelial cells with variably staining cytoplasm. Nucleocytoplasmic ratio 1:4-1:5. Smaller and less intensely PASpositive goblet cells with poorly defined cellular borders and marked decrease in number.

Grade 3: Large and polygonal epithelial cells with basophilic staining cytoplasm. Nucleo-cytoplasmic ratio greater than 1:6 and absence of goblet cells.
The findings of grades 2 and 3 on the interpalpebral conjunctiva suggest a diagnosis of dry eye. Parameters between the groups were analyzed by the Student t-test and analysis of variance with SPSS software. The Mann-Whitney $U$ test and Kruskal-Wallis test were used for the analysis of nonparametric values such as grade of conjunctival squamous metaplasia. A P-value of less than 0.05 was considered statistically significant.

\section{Results}

The study comprises 100 patients, 50 smokers and 50 ages matched non smokers. The mean age of the smoker 35.5 years \pm 7.64 years and the mean age of non smokers in control group was $33.60 \pm 5.54$ years with insignificant statistical difference. In our study, $42 \%$ of the subjects in the smoker group had history of smoking of 5 to 10 years and $24 \%$ had history of $10-15$ years. Amongst 50 smokers, 52\% $(n=26 / 50)$ were light smokers, $30 \%(n=15 / 50)$ were moderate smokers and $18 \%(n=9 / 50)$ were heavy smokers.

Redness (34\%) was the most common symptom of smoker followed by ocular tiredness (26\%), burning sensation (24\%), itching (24\%) and foreign body sensation (14\%), however most of the smokers were asymptomatic at the time of presentation (36\%). OSDI score was $32.85 \pm 20.79$ in smokers as compared to $20 \pm 8.4$ in non smokers with significant statistical difference $(p<0.001) \quad($ Table 1). Furthermore, Symptom score was highest among heavy smokers (44 \pm 6.8$)$ and lower $(25 \pm 7.2)$ among mild smokers, however the difference was not statically significant $(p=0.65)$ (Table 2).

Table 1: Clinical and pathological profile of smoker's vs non smokers

\begin{tabular}{|c|c|c|c|}
\hline & Smokers & Non smokers & P-value \\
\hline Mean Age & $36.40 \pm 7.64$ & $33.60 \pm 5.54$ & 0.06 \\
\hline $\begin{array}{c}\text { Tear Film Break Up } \\
\text { time(TBUT) (Seconds) }\end{array}$ & $14.69 \pm 4.34$ & $11.07 \pm 2.29$ & 0.001 \\
\hline Basal tear secretion(mm) & $12.58 \pm 2.79$ & $10.40 \pm 2.64$ & 0.001 \\
\hline OSDI score & $32.85 \pm 20.79$ units & $20 \pm 8.4$ & $<0.001$ \\
\hline $\begin{array}{c}\text { Conjunctival squamous } \\
\text { metaplasia }\end{array}$ & $2.35 \pm 1.02$ & $1.02 \pm 0.54$ & $<0.001$ \\
\hline
\end{tabular}

Mean tear film break up time in non smoker was $14.71 \pm .34$ seconds as compared to $11.25 \pm 2.29$ seconds in smokers with statistically significant difference $(p=0.0001)$ (Table 1). TBUT was lower in patients with heavy smokers (9.54 seconds) as compared to 11.73 seconds in mild smokers, however the difference among the three group was not significant $(p=0.03)$ (Table 2).

Table 2: Clinical and pathological finding in mild, moderate and heavy smokers

\begin{tabular}{|c|c|c|c|c|}
\hline & $\begin{array}{c}\text { Mild (<10 } \\
\text { cigarettes /day) }\end{array}$ & $\begin{array}{c}\text { Moderate (11-20 } \\
\text { cigrettes/day) }\end{array}$ & $\begin{array}{c}\text { Severe (>20 } \\
\text { cigrettes/day) }\end{array}$ & p value \\
\hline $\begin{array}{c}\text { Sympom scored } \\
\text { (OSDI) }\end{array}$ & $25 \pm 7.2$ & $36 \pm 5.6$ & $44 \pm 6.8$ & 0.67 \\
\hline $\begin{array}{c}\text { Mean Basal tear } \\
\text { secretion (mm) }\end{array}$ & 11.5 & 9.4 & 8.77 & 0.002 \\
\hline Mean TBUT (sec) & 11.72 & 10.28 & 9.54 & 0.03 \\
\hline $\begin{array}{c}\text { Squamous } \\
\text { metaplasia } \\
\text { (Grading Mean) }\end{array}$ & 0.73 & 1.40 & 1.55 & 0.002 \\
\hline
\end{tabular}


Mean score of Schirmer's test was $12.58 \pm 2.79$ seconds in non smokers as compared to $10.40 \pm 2.64$ seconds in smokers with significant statistical difference $(p=0.001)$. In subgroup analysis, mean schirmer's test was $8.77 \mathrm{~mm}$ in heavy smokers as compared to $11.5 \mathrm{~mm}$ in mild smokers $(p=0.002)$.

On impression cytology, $20 \%$ of the subjects in smoker group shows grade 2 metaplasia and $8 \%$ showed grade 3 metaplasia (Figure 1) in comparison to $2 \%$ and $0 \%$ in non smoker group respectively $(p=0.0001)$. In sub group analysis, $22.2 \%(n=2 / 9)$ of subjects showed grade 3 metaplasia as compared to $6.7 \%(n=1 / 15)$ and $3.8 \%(n=1 / 26)$ in moderate and mild smokers respectively $(p=0<.002)$.(Table 3$)$.

Table 3: Impression cytology grading in smokers vs non smokers

\begin{tabular}{|c|c|c|}
\hline Grading & Smokers $\mathbf{n}(\%)$ & Non Smokers (\%) \\
\hline Grade 0 & $12(24 \%)$ & $38(76 \%)$ \\
\hline Grade1 & $11(22 \%)$ & $24(48 \%)$ \\
\hline Grade 2 & $01(2 \%)$ & $10(20 \%)$ \\
\hline Grade 3 & $0(0 \%)$ & $04(08 \%)$ \\
\hline & & P- value $=0.0001$ \\
\hline
\end{tabular}

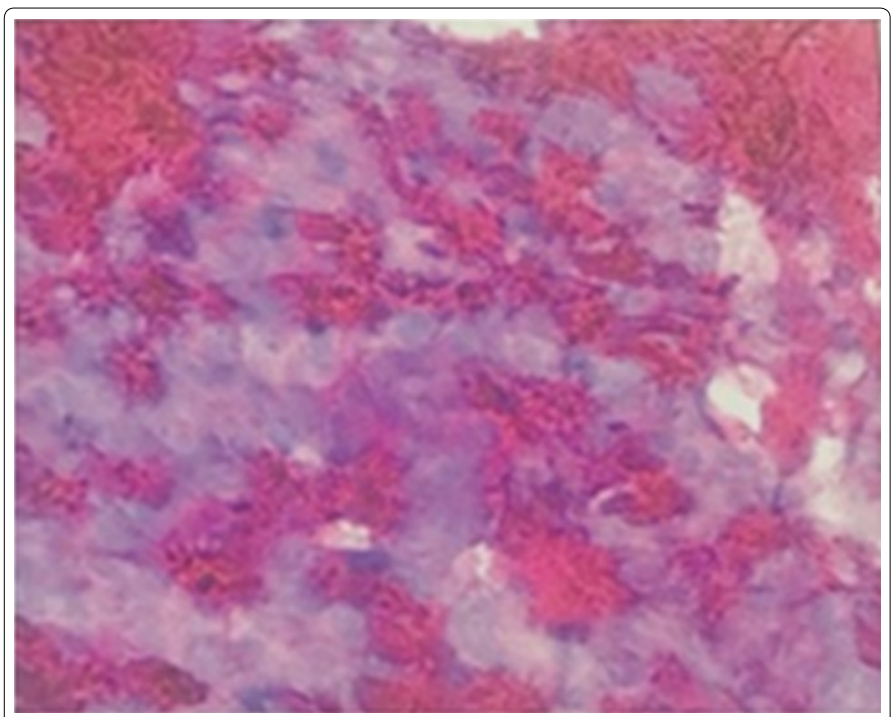

a

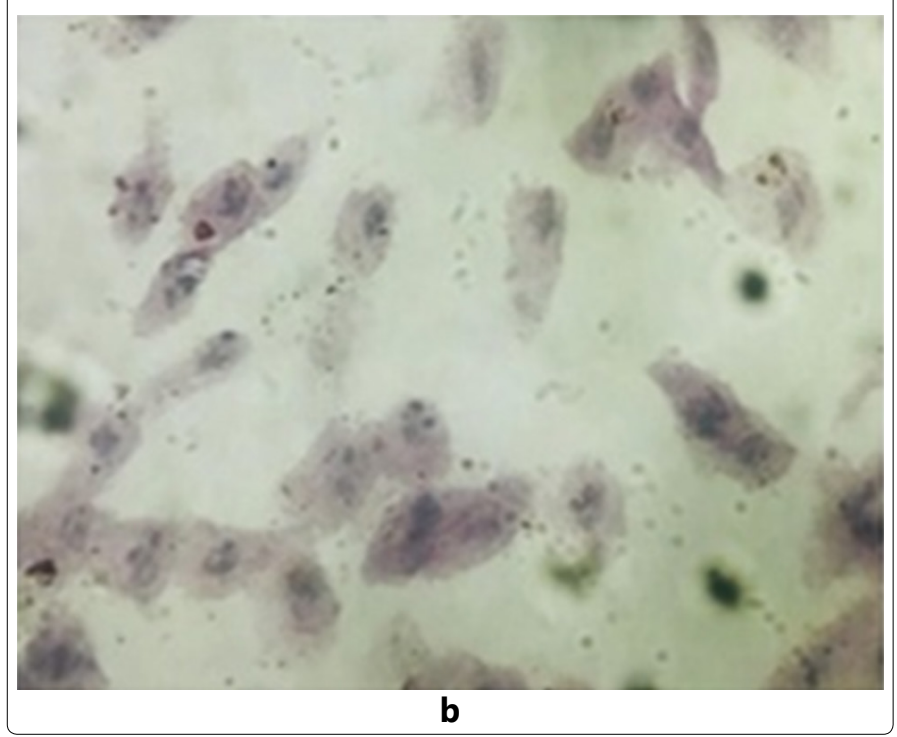

Figure 1: (a) Impression cytology of non smoker Subject with abundant goblet cells and intense positive cytoplasm, small round epithelial cells with nucleo-cytoplasmic ratio of 1:2 (b) Impression cytology obtained from chronic smoker subject showing loss of goblet cells and larger

polygonal epithelial cells with nucleo cytoplasmic ration of 1:6

\section{Discussion}

The ocular surface is covered by a tear film for lubrication which plays a major role of nutritional route for corneal epithelium. Cigarette smoke is a well-known, significant source of toxic minerals and heavy metals, including more than 4000 toxic chemical substances. Epidemiological studies [7] have shown that cigarette smoking may be a high-risk factor for several ophthalmological disorders, including cataract, agerelated macular degeneration, and dry eye disease.

In our study, there was increased prevalence of smoking in subjects of rural background and maximum number of smokers lies in age group of 30 to 40 years (Mean age of $36.4 \pm 7.6$ years). Li-xu et al. [5] in metanalysis have suggested several pathogenesis of dry eye including chronic inflammation of the ocular surface, decreased sensitivity of cornea and conjunctiva, reduction of production and/or stability of tears, and epithelial damage. Similarly, Kjaergard et al. [9] also reported a higher degree of ocular irritation among tobacco workers who came in contact with a high concentration of the substance. In the present study, the eye irritation scores and indices of smokers were statistically higher than those of nonsmokers. The indices of symptom score was dependent on rate of smoking and was higher in heavy smokers as compared to mild and moderate but the difference was not statistical significant.

Several studies have reported a significant correlation between eye irritation and reduced TBUT and/or epithelial damage in smokers as compared those of non-smokers. Avunduk et al. [12] determined a deterioration of projections and loss of microvilli, which are important for stabilising the tear film in conjunctiva exposed to tobacco smoke. In our study, TBUT was lower among smokers as compared to non smokers with significant statical difference. This was attributed to deficiencies in lipid layer of tear film due to tobacco smoke. Although, TBUT was lower in heavy smokers as compared to mild and moderate smokers but the difference was not significant.

In our study, basal tear secretion (schirmer's 2) test value was lower in smokers (10.40 seconds) as compared to non smokers (12.58 seconds). Our results were in contrast with the study conducted by Satici et al. In their study, Schirmer's test 1 value were higher in smokers as compared to non smokers which was attributed to reflex tear secretion. However, the Yoon et al. [10] reported that basal tear secretion was significantly lower in the smoking group. It is believed that tear film lipid layer minimise the evaporation of aqueous component of the tear film in physiologic state however the negative impact of cigarette smoking in lipid layer is the main cause of deterioration. Our study found that there is a decrease in basal tear secretions (Schirmer's 2) similar to earlier studies conducted in the past, however there is an increase in reflex tear secretion thus increase in total secretion is seen among smokers.

Altinors et al. [11] found an increase in polymorphonuclear leucocytes and squamous epithelium cell counts both before and after a work shift among tobacco workers, when compared 
to their referents. Conjunctiva exposed to cigarette smoke exhibit certain changes similar to those in eyes exposed to chronic irritation. Avunduk et al. [12] determined that tobacco smoke altered the conjunctival structure in rats by causing squamous metaplasia in the conjunctiva surface epithelial layer. Satici et al. [13] also reported that the degree of squamous metaplasia among smokers was higher that of control group. Uchino et al [8] in their study also concluded that smoking is associated with ocular surface inflammation which leads to decreased tear secretion, goblet cell density and tear MUC5AC concentration. Our study has found a higher grade of squamous metaplasia in smokers as compared to non smokers. Grading of Sqaumous metaplasia was significantly higher in smokers as compared to non smokers. Furthermore, metaplasia was associated with amount of smoking. Heavy smoking was associated with significant higher grade of ocular surface damage as compared to mild and moderates smokers. Our study further strengthens the establishment of positive correlation with the amount of smoking. This is attributed to the inflammation associated with irritative and toxic agents associated with cigarette smoking. Thus from the above finding it can be inferred that smoking has a deleterious effect on ocular surface leading to tear film abnormality and conjunctival squamous metaplasia.

\section{Conclusion}

In our study we conclude that Smoking is a significant risk factor in the development of dry eyes and ocular surface disorder characterised by squamous metaplasia and loss of goblet cells. Furthermore the severity of dry eyes has positive correlation with amount of smoking.

\section{References}

1. Solberg $Y$, Rosner $M$, Belkin $M$. The association between cigarette smoking and ocular diseases. Surv Ophthalol. 1998; 42(6): 535-547.

2. Kelly SP, Thomson J, Edwards R, Sahu A, Harrison R. Smoking and cataract: review of casual association. J Cataract Refract Surg. 2005; 31(12): 23952404. doi:10.1016/j.jcrs.2005.06.039

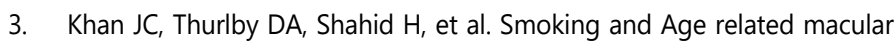
degeneration: The number of pack years of cigarette smoking is a major determinant risk for both geographic atrophy and choroidal neovascularisation. Br J Ophthalmol. 2006; 90(1): 75-80. doi: 10.1136/bjo.2005.073643

4. Albenz J, Begley C, Schein O, CafferyB, Nichols K, Schaumberg DA. The epidemiology of dry eye disease: report of the Epidemiology Subcommittee of the International Dry Eye WorkShop (2007). Ocul Surf. 2007; 5(2): 93-107. doi: 10.1016/S1542-0124(12)70082-4

5. Xu L, Zhang W, Zhu XY, Suo T, Fan XQ, Fu Y. Smoking and the risk of dry eye: a Meta-analysis. Int J ophthalmol. 2016; 9(10): 1480-1486. doi: 10.18240/ijo.2016.10.19

6. https://static1.squarespace.com

7. Bron A, Evans VE, Smith JA. Grading of corneal and conjunctival staining in the context of other dry eye tests. Cornea. 2003; 22(7): 640-50.

8. Uchino $Y$, Uchino $M$, Yokoi N, et al. Impact of Cigarette Smoking on Tear Function and Correlation between Conjunctival Goblet Cells and Tear MUC5AC Concentration in office Workers. Sci Rep. 2016; 6: 27699. doi: 10.1038/srep27699

9. Kjaergaard SK, Pedersen of. Dust exposure, eye redness, eye cytology and mucus membrane irritation in a tobacco industry. Int Arch Occup Environ Health. 1989; (61): 519-525.

10. Yoon KC, Song BY, Seo MS. Effect of smoking on tear film and ocular surface. Korean J Ophthalmol. 2005; 19(1): 18-22. doi: 10.3341/ kjo.2005.19.1.18

11. Altinors DD, Akca $S$, Akova YA, et al. Smoking associated with damage to the lipid layer of the ocular surface. Am J Ophthalmol. 2006; 141(6): 10161021. doi: 10.1016/j.ajo.2005.12.047

12. Avunduk AM, Avunduk MC, Evirgen $O$, et al. Histopathological and ultrastructural examination of the rat conjunctiva after exposure to tobacco smoke. Ophthalmologica. 1997; 211(5); 296-300. doi: 10.1159/000310812

13. Satici A, Batiren M, Ozardali I, Vural H, Kilic A, Guzey M. The effect of chronic smoking on the ocular surface and tear characteristics; a clinical, histological and biochemical study. Acta ophthalmic stand. 2003; 81(6): 583-587. doi: 10.1111/j.1395-3907.2003.00158.x 